\title{
The Research on "Fight" Culture in Chinese Traditional Games
}

\author{
Sun Yuechuan, Bein Kaixuan \\ School of Foreign Languages, Southwest Petroleum University, Chengdu, China \\ Email address: \\ 89339775@qq.com (Sun Yuechuan), evelynbian@163.com (Bein Kaixuan)
}

\section{To cite this article:}

Sun Yuechuan, Bein Kaixuan. The Research on "Fight" Culture in Chinese Traditional Games. Communication and Linguistics Studies. Vol. 7, No. 2, 2021, pp. 38-43. doi: 10.11648/j.cls.20210702.13

Received: June 2, 2021; Accepted: June 19, 2021; Published: June 30, 2021

\begin{abstract}
In traditional Chinese games, there is a basic element of "fight", which is similar to the competition culture in western games, but deeply influenced by traditional Chinese culture and develops to a "fight" culture with Chinese characteristics. As for the tradition Chinese games, there are different kinds of games with "fight" element, such as the game of verbal fight and martial fight, which have different emphasis and evolution process. Most of traditional Chinese games with fight element have characteristics of long history and rich cultural heritage, educational significance being more important than entertainment, and abundant seasonable games. As an important part of folklore, these games with "fight" element reflect the cultural characteristics of the Chinese nation with its unique existence, including the contradiction between the cultures of constantly fighting for self-improvement and harmony, emphasis on collectivism, emphasis on practice over theory, obvious gender distinction, obedience to the authority of rules. In this paper, the author will analyze the traditional Chinese games, especially those games with "fight" cultural elements, and explore the characteristics of such games and the cultural background and national spirit reflected, so as to provide a reference for the further development and dissemination of traditional Chinese games today.
\end{abstract}

Keywords: "Fight" Culture, Emphasis on Harmony, Collectivism, Gender Distinction, Obedience to the Authority of Rules

\section{Introduction}

Chinese traditional games refer to various interesting activities for amusement in people's daily life which have been handed down from ancient times. These interesting activities form an ancient cultural tradition and commonly known as "play" for its amusement. "Play" has a long history in China, and the written records about them are even very early. As Cai Fengming identified in the history of the game, "China has a long history of gaming. If we count from the ancient games recorded in the history of pre-Qin period, such as cockfighting, dog-racing, liubo chess and kicking ball, Chinese games have a history of thirty-four thousand years. And if the archaeological materials excavated underground are considered, the history of Chinese games can be traced back to the remote primitive times [2]."

In the process of long-term accumulation, Chinese traditional games become rich and varied as a result of the integration of the games handed down and created from generation to generation. According to the record in
Encyclopedia of Chinese Traditional Games written by Ma Guojun, there are more than 100 kinds of traditional games in the history [7]. He classified them into 13 categories, which include wrestling game, drinking game, board game, gambling game, ball game, throwing game, shooting game, water game, ice and snow related game, oral literature game, fire related game, captive game and miscellaneous game.

Various traditional games enrich the leisure life of Chinese people. As an important part of Chinese traditional culture, they also show the charm of unique Chinese culture, and display the typical personality of the Chinese nation. Among them, there is a particularly basic element of "fight" in most traditional Chinese games. It is similar to the competition culture in western games, but a unique Chinese "fight" culture forms by the effect of Chinese traditional culture.

This paper will analyze the traditional Chinese games, especially those games with "fight" cultural elements, and explore the characteristics of such games and the cultural background and national spirit reflected, so as to provide a reference for the further development and dissemination of 
traditional Chinese games today.

\section{Types and Evolution of the "Fight" Element in Traditional Chinese Games}

"Fight" is interpreted literally as two sides fight with each other for the victory with their strength or intelligence. "Fighting" games mean that people play games aimed to fight for victory [3]. It first appeared in Menglianglu, written by Wu Zimu in Song Dynasty: "Maids in forbidden palace play games through fighting grasses [14]."

In traditional Chinese games, there are a number of games with the element of "fight". From the perspective of the name, some are directly endowed with the word of "fight", such as bullfighting, cricket fighting, grass fighting, chicken fighting, duck fighting, goose fighting, quail fighting, ant fighting, etc. Although some are not named "fight", the fighting process is actually the theme throughout the whole game, such as wrestling, kicking ball, Weiqi, Chinese Chess and so on. From the perspective of the mode, some are mainly the battle of physical strength, commonly known as "martial fight", such as tug-of-war, dragon boat race, wrestling with shoulder, chicken fighting, etc. Others are the competition of brains, namely "verbal fight", like Chinese rope weaving, poetry game, pairing game, national chess, etc. From the view of the participant, people directly participate in some games, such as wrestling, "chicken" race, copper cash throwing game and Chinese Chess. In other games, the direct participants are plants and animals, such as cricket fighting, sheep fighting, duck fighting, bird fighting, dog fighting, fish fighting, grass fighting and melon fighting. These games involved by the plants and animals are representative of and account for the high proportion of the Chinese traditional games with "fight" element.

"Fight" keeps fighting and confrontation as the core, accompanied by the comparison, wrestling and competition between the two parties. On the one hand, martial fight is not only a kind of game, but also a competition among opponents. In martial fight, both sides should fight against each other in the process of competition with the purpose of victory. For example, chicken fighting game, is to make use of the combative characteristics of chickens in a special period and artificially make them fight each other to compete. Chicken fighting was first seen in Tso Chuan: "Ji's and Hou's chicken fights. Ji sprinkles mustard on his chicken, and Hou puts a metal knife on his chicken [5]." It means that Ji Pingzi sprinkles mustard on his chicken wings (or paints the feathers with glue to make them similar to armor), and the Duke of Hou Zhao puts a metal knife on his chicken feet. As early as the Warring States period, chicken fighting game is very popular. As stated in Stratagems of the Warring States, "Linzi was very rich and abundant in wealth. All people there can play Yu, Se, Zhu, Chinese Zither, chicken fighting and walking dog [10]." According to Historical Records, "Ang was free from illness and lived at home... fight chickens and walk dogs with each other [9]." In the earliest time, chicken fighting game is one of the common folk fighting dramas. People fight chickens with each other for victory. In Tang Dynasty, chicken fighting game becomes more and more prosperous, and gradually separated from the scope of simple entertainment games into a special sports activity. During the period of Emperor Xuanzong of the Tang Dynasty, large-scale chicken fighting competitions are often held in Chang'an, especially in the Lantern Festival, Qingming Festival and Mid-Autumn Festival. Emperor Xuanzong of the Tang Dynasty gathers people to fight chickens for showing the peace of the world. Tang Dynasty writer Chen Hong recorded in Biography of East City Men: "Emperor Xuanzong (712-756 AD) played the folk chicken fighting during the Qingming Festival before ascending the throne. After the accession, the chicken house was built between the two palaces, and a lot of chickens were raised there, including thousands of Jinhao, Tieque, Gaoguan and Angwei [1]." Evolved from the game to the competition, the entertainment element of the game is weakened, and the competition significance is strengthened. It becomes an independent fighting project, which takes the victory as the purport and the result as the goal. also known as cripple fighting and cripple bumping, is a game that children usually play in winter to train their balance force and endurance. Chicken fighting game is originally children's play and a typical fighting game. It requires at least two people to stand on his one foot and hit each other with their knees. With the development of its competitive factors, chicken fighting gradually broke away from an entertainment game to a sports game, namely the foot fighter competition. In the change from entertainment to competition, the entertainment element of game is weakened, and the competition element is strengthened. The fighting game pursues the victory as the interest and the result as the orientation.

On the other hand, although verbal fight is a kind of fighting game, its pursuit of fun differs from martial fight in that it mainly focuses on displaying participant's intelligence and skills. Participants tend to display strategies or literary talent as much as they can in the process, and enjoy the fun of the game. It is necessary, but not the only purpose to win the game. For example, Weiqi, namely "chess" in ancient China and "Go" in western countries, is a strategic chess game with two players. Weiqi has been widely spread as "Yi" as early as the Spring and Autumn period and the Warring States period. For example, Confucius wrote in Analects of Confucius, "It's hard to eat all day without any intention. It is an activity of sage to fight with Yi [11]." In the game of Weiqi, the black and white piece respectively represents one side. Two sides decide how to move his own pieces and solve the offensive of the other side based on personal intelligence and strategy. The final victory is determined by the number of pieces left on the board. Nowadays, Weiqi has become a world game with the participation of the best players from various countries. Although the final result contains both the victory and the failure, Weiqi is less competitive than martial fight games, and the winner is not determined by a game. Instead, they are ranked according to the games of different levels. In addition, there formed a set of special terms about 
Weiqi, and the game between top players, often conserved to repeatedly analyze and research, is endowed by the feature of culture. It can be said that Weiqi game doesn't focus on competition, but on the position distribution in the game, as well as the further strategies and interests of the players. As for Jiuling, Shizhong and Shudui, they tend to display the participants' talent and wisdom and the aggressive willingness is greatly weakened.

\section{Characteristics of Chinese Traditional Games with "Fight" Element}

Cai Fengming pointed out, "There is often a fixed uniformity in people's behavior style. After the accumulation of a long period, the game custom with local features gradually formed from people's behavior style. These customs are mainly reflected in the organization process, the competition process of games, the lifestyle related to these games activities and so on [2]." The traditional games with "fight" element develop from the traditional Chinese culture and reflect a series of distinctive game customs with Chinese characteristics after the inheritance of many generations.

First, the traditional games with "fight" element have a long history with an abundance of Chinese historical and cultural heritage. The traditional games with "fight" element are not only for entertainment, but also have profound cultural accumulation, including cultural allusions, historical stories and poetry. For example, Chinese chess simulates the ancient wars, which is originated from the rivalry history between $\mathrm{Chu}$ dynasty and Han dynasty, and its chess board is divided by a boundary named Chu's river and Han's wall. Chinese chess is listed as an art for self-cultivation of ancient literati and officialdom because of the integration of culture, science, art and competition. Also, according to legend, horn fighting game originates from the great war of Central Plains in the ancient period. At that time, when fighting with the Yellow Emperor's tribe, Chiyou used a special method by attacking with horn ware on their heads. Thus, horn fighting game is also called Chiyou play. Additionally, some games do not have particular cultural origin, but they have been mentioned many times in ancient poetry because of their widely spread. For example, flying a kite is a very popular folk game with "fight" element. Many ancient verse record the scene of flying a kite, such as "the most interesting thing for children is flying a kite above the eaves tile", "when children suddenly clap their hands together, a kite is blown down with the pine tail", "the children who return from school early are busy in flying kites with the east wind". Therefore, flying a kite is always seen as a special cultural background and one of the representative Chinese traditional cultures.

Second, Chinese traditional games with "fight" element put emphasize on social civilizing thoughts more than the purpose of entertainment. They stress the cultural spirit reflected behind games. Unlike the western games with "fight" element, although Chinese traditional "fight" games emphasize competition, they value the cultural spirit behind competition, and thus promote to civilize the society, other than the result of competition. For example, the traditional game "image of dice-throwing for promotion" is based on the culture of ancient Chinese civil service system. People use schema, dice and chips to play the game according to the settled rules, and the people who promote to a higher position win the game. In addition to the competition in the game, it combines the historical background in the ancient time to teach children to understand the official system and the ban on bribe. Another example is "wooden posts striking". In this game, 15 wooden posts are erected in front of people, and the players should throw the ball on the ground to knock down these posts. These wooden posts are respectively engraved with the words of "loyalty", "righteousness", "propriety", "wisdom", "trust" and other tenets. This game aims to civilize the people to pursue good virtue in the entertainment, so that the game also serves for moral education.

Third, Chinese traditional games with "fight" element are mostly related to the change of season and festival. "China adopted the Gregorian calendar in 1912, the first year of the Republic of China, but our own yin and yang calendar, namely the lunar calendar was still in use. In a way, a calendar and dating method reflects a culture and lifestyle [12]." The lunar calendar is a unique method of dating in China, which is rooted in the ancient agrarian society. According to the lunar calendar, the date of festivals corresponds to the timing sequence of nature and humanity, and the production and life rules of people. Thus, people always play the specific game on the date of season and festival, such as lion dancing and plucking the greens on the Spring Festival, riddle guessing and tug-of-war on the Lantern Festival, Cuju and flying a kite on the Qingming Festival, dragon boat racing, grass fighting and shooting from the willow on the Dragon Boat Festival, girl's intelligence fight on the Qixi Festival, flying a kite on the Double Ninth Festival and traditional games like sumo at the ancient temple fair.

\section{The Cultural Connotation of "Fight" Reflected in Chinese Traditional Games}

As an important element of folklore, Chinese traditional game develops in the atmosphere of traditional culture. Under the influence of various factors, such as geography, climate, customs, and psychology, traditional games often shows the local people's lifestyle, thinking mode and customs in the aspect of the content and mode of presentation. Particularly, the games with "fight" element reflect the cultural characteristics of China in a unique way.

First, they dare to struggle and constantly strive for self-improvement, but advocate harmony as the most important, which shows the contradictory nationality. Chinese nation originates in a vast area centered on the Yellow River Basin. Human's living environment is extremely harsh. In Yellow River Basin, floods and droughts hit people constantly and vipers and beasts thrive in dense forests, swamps, and 
bushes spreading all over the area. Due to the complex geographic environment and low productivity level, ancient Chinese people have to live in a world full of natural disasters. Compromise means death. Thus, in order to survive, the ancestors have to fight against them. The fighting spirit of the ancestors toward suffering can be reflected in the myths, which show the understanding of the world, such as Pan Gu creating heaven and earth, the goddess named Nv Wa mending the sky, King Yi shooting down nine suns and Jingwei filling up the sea. Since then, the Chinese nation succeeds to the great spirit of constant self-improvement to fight from generation to generation, and forms the tradition of fighting against nature, earth, and enemy. Assimilating the elite of this tradition, a large number of games have the spirit of finding delight in fight.

However, the rules of the game originate from the "fight" culture, but do not take it as the main spirit. It puts emphasis on harmony as a moral standard, which contradicts the "fight" culture. For example, Shi Bo in late West Zhou dynasty proposed "Harmony vitalizes everything [4].", and Yan Ying proposed "The predecessor blend the five flavors, make the harmony of the five sounds, to calm the mind and make success of the politic [5]". In the chapter of Xue Er of the Confucian Analects, it is also put forward that "In the practice of art, what is valuable is natural spontaneity [11]." Confucius regarded harmony as the highest stage of handling affairs and rituals. Since then, the culture of moderation and harmony has become another important Chinese nation spirit. This spirit in the game shows that people would rather enjoy the playing process and dilute the risk of fierce conflict to pursue the outcome of the game. In a word, the two contradictory nation spirits, "fight" spirit and emphasis on harmony coexist in traditional games and create a distinctive Chinese-style "fight" culture.

Second, there is an obvious tendency of collectivism which valuing team. In the games with "fight" element, group games are the majority, while the games with strong personal characteristics are relatively few. Among them, there are games characterized by the mutual attack between groups, such as kicking ball, tug-of-war and dragon boat race, etc. There are also games with groups working together for a target, such as catching a "thief", game of chicken, etc. Also, although players compete with individuals in some games, there is still some collectivistic element to the games. For example, in Weiqi and Chinese Chess, players compete with each other, but various pieces on the board form a team. In cripple bumping and pitch-pot game, players also perform a one-on-one confrontation in each round. But practically, the participants are generally divided into groups, which means that these games tend to be played in the form of group than in individuals. So the game atmosphere is "lively" but not "cold". At the same time, the success or failure of the game is often based on the team, rather than individual's victory or failure.

In fact, collectivism tendency has a long history. Since ancient times, Chinese people have always lived in the collective. "From clan, tribe to state, with the continuous expansion of the collective scale, individuals are bound more and more tightly by the blood ties [15]." With the development of clan system in the Western Zhou dynasty, individuals had to obey clan system absolutely when dealing with life and production affairs, because individuals lacked discourse right and had to rely on clan to survive. Since then, the sense of collectivism has become stronger. After Qin Shi Huang unified China, the collectivism was further expanded and developed. At the same time, a set of ethical norms corresponding to the collective life became stricter. It made the individual's freedom and personality nipped away, replaced the independent personality and human rights, so that the individual was replaced by the collective. In the whole national culture, a deep-rooted concept of collectivism has formed, that is, the collective is greater than the individual, the collective is more valuable than the individual, and the collective precedes the individual. Therefore, Chinese people become used to collective spirit and life, and various customs show an obvious tendency of collectivism. And traditional games even reflect the common thoughts of this nation. They are always presented in a group, forming a trend of collective games.

Third, there are some "fight" games about science and technology which shows the talent of Chinese nation, but modern scientific research was not developed for the absence of theory. "Fight" games about science and technology refer to the games combined with scientific principles, not only including the small experiments, inventions and toys designed by scientific principles, such as the characters floating on the water, flower forcing game, Chinese ring puzzle, jigsaw puzzle, but also including games that do not directly reflect scientific principles but contain them in the process in order to make players raise questions and explore the scientific knowledge actively, such as diabolo, gyro, trotting horse lamp, etc. Scientific games are numerous and have a long history, which cover many disciplinary areas, like physics, chemistry, biology, agriculture, animal husbandry, plant cultivation, calligraphy and painting. These games show that science and technology existed in ancient China, and it is even quite advanced in that period. Unfortunately, China's ancient technology is not continued and developed continuously, leading to today's backward technology. It is probably resulted from the Chinese traditional culture which emphasis on practice over theory.

China's ancient science and technology originates in an early time. "China's scientific discoveries and inventions far exceeded those of Europe at the same time, especially before the 15 th century [8]," Joseph Needham said. Scientific games are produced on this basis. Taking competition as a means, they cultivate children's science and technology awareness and interest, and provide an opportunity for the further development of science and technology. However, in fact, ancient Chinese science and technology leading the world does not produce the corresponding modern science. This confusion is first proposed by Joseph Needham in his book The History of Science and Technology in China, and is known as the "Needham puzzle" in the academic world. In order to solve this problem, many scholars conducted in-depth 
discussions. Mr. Jin Yuelin pointed out that the reason why China did not take the lead in producing modern science was, in the final analysis, "because there was not a developed sense of epistemology and logic in China [6]". To put it simply, the Chinese people traditionally rational and logical thinking, and they have intuitive and perceptual thinking mode instead. Ancient Chinese science and technology originates from the labor practice of the masses, and it is widely applied for mathematics, astronomy, agriculture, medicine and other practical fields, which is significant for the development of Chinese traditional economy and society in the practice. However, when many scientific inventions were created, people paid more attention to improve the production and living standard, but seldom made theoretical research on this basis. Therefore, the rational construction of modern science and technology was not formed as in the West.

Fourth, participants of "fight" game have a clear gender distinction. The game participants are mainly male, while most women stay away from the fight. China has been deeply influenced by the Three Cardinal Guides and the Five Constant Virtues, the social political and moral concepts of Confucianism, which formed the traditional concept of gender distinction. Book of Rites mentions: "If a boy is born, his parents will hang a bow on the left of door. If a girl is born, her parents will hang a towel on the right of door [13]." Men and women seem to be born with differences. In the growth and life, women are taught to abide by the rules of good and virtuous words and deeds, and to keep them at home, and they are not able to leave boudoir easily. The main work of women is to take care of their parents and children in their families. They seldom show up in the public, and are more unlikely to fight with others. Men, on the contrary, have been taught since childhood that it is their duty to benefit the world. They have greater power and freedom, and are encouraged to make progress actively, so that they can reach the higher class in all kinds of struggles.

Therefore, the traditional games aimed for moral education tend to be designed for men as the participants, which brings about that the traditional games played by men are far more than that by women. Among them, the games that completely designed for women count only a few, such as girl's intelligence fight and play colorful ball. The games that consider women players are also rare, such as swinging, kicking shuttlecock, throwing stones, flowers and plants fight, etc. These games are also aimed at the intension of moral education, yet the purpose of them is to emphasize the feminine morality and femininity because the player is a woman. On the contrary, the games entirely designed for men are numerous. There are chess game, like Chinese Chess and Weiqi, ball game, like polo and kicking ball, and various kinds of physical confrontation game, like cripple bumping and horn fighting game. These games not only require participants to be male, but also reveal a male chauvinism during the game. Take Chinese Chess as an example. Each chess piece on board is set around the king in order to protect him, which reflect the traditional view of being loyal to the ruler. And all the pieces are invariably male characters without woman, reflecting strong male chauvinism that only man could be politician in the ancient time. That is not only the performance of the feudal society, but also shows the bias of "fight" culture in the gender choice. Certainly, both men and women today can participate these traditional games, but the rules of the game itself reflect the gender consciousness of the traditional "fight" culture.

Fifth, "fight" game reflects the traditional hierarchy, and there is a strong tendency of authority and strict rules. From Confucius' doctrine of "rites", which established the hierarchy of "the emperor is the emperor, the minister is the minister, the father is the father, and the son is the son", to Dong Zhongshu's Three Cardinal Guides and the Five Constant Virtues, which was established after "disbanding all schools of thought and respecting Confucianism alone", an absolute worship of authority and a consistent adherence to hierarchy in Chinese society forms not only in system, but also in people's mind. That collective unconsciousness inherited in history, to a certain extent, is linked to the autocratic system superior to China for thousands of years. Zhang Hongjie pointed out that "Autocratic system is a poisonous needle pricked by the predator on the nerve of Chinese society. It turns Chinese society numb, rigid and unable to resist, so that the predator can strike into the bone and suction marrow without restraint. Therefore, the greatest invention of the Chinese nation is not the "Four Great Inventions", but autocratic system. It's a technology with profound theory, sophisticated design, and huge system [15]." Under this huge system, traditional games are used as a tool for social education, which is hard to separate from the shackles of autocracy.

For one hand, since these Chinese "fight" game are created, they follow relatively fixed rules and these rules are passed on by following generations. Although people make proper adjustment with the change of time and region, the basic process, mode and theme are relatively constant in general. Under the fixed program, the particularity of the game enables it to spread the traditional Chinese wisdom better. For example, grass fighting requires two sides to hold grass and pull, and the victory is decided by the pulling force on both people and grass. Participants must have a certain understanding of all grass objectively for the win. Thus, grass fighting serves as an important means for people to get close to and understand nature. Abiding by the game rules not only inherits the traditional games, but also popularizes the herbal knowledge.

For another hand, the excessive compliance and adaptation to the rules and authority in the traditional games, to a certain extent, also leads to the lack of resistance and innovation consciousness in the game education, which has a relatively negative impact on the cultivation of social creativity in the ancient time. When people play games, they must follow the fixed rules at that time. They can't change rules according to their own ideas or create new temporary rules. For example, "game of chicken" concludes three kinds of roles: eagle, hen and chickens. The player who plays as the role of hen needs to protect the players who play the role of chicken behind, and the player who plays as the role of eagle circles to catch chicken. Chicken behind the hen can only avoid by dodging 
left and right, but can't fight back. In practice, participants consistently follow this rule and play their roles. People of the Yi nationality have a similar game called "female bird versus eagle". The rules are similar to those of the Han nationality. But in practical, Yi chickens can fight back or even hurt Eagles according to the situation at that time. This obvious difference shows that there are differences between Han and Yi nationality in their awareness and attitude towards the established rules. Han nationality are more willing to abide by the rules, while Yi tends to break the rules from time to time.

\section{Conclusion}

As an important part of Chinese culture, the traditional game with "fight" element plays a significant role in cultural education and communication, national consciousness formation, children's intelligence and physical strength development, and moral character shaping. However, with the development of society and the continuous innovation of communication and transportation networks and other technologies, the venue, materials and time participants of traditional games have been weakened and reduced to a certain extent. A large number of new games, such as computer games, online games, Lego models and so on, have greatly squeezed the development space of traditional Chinese games.

Game, as an important way of entertainment, is one of the best preservers and inheritors of national culture. The "fight" culture shown in the "fight" element games is one of the cores of Chinese culture, which is clearly national and unique. Among them, the national spirit of "emphasis on harmony" and fighting should be vigorously carried forward and developed. Facing the challenges of various new games in the new era, it is necessary to consider how to revitalize the traditional games and gain a place in the competition to inherit and carry forward, and be accepted by more regions and countries.

\section{Acknowledgements}

This research has been partially supported by the Research Project of Postgraduate Teaching Reform and Research of Southwest Petroleum University of Sichuan Province in 2020 under grant No. JY20YB15 and the Project of English Translation under the Intercultural Perspective of exemplary postgraduate tutors in "Three-wide Education" Reform of Southwest Petroleum University in 2021.

\section{References}

[1] Biography of East City Men. http://www.360doc.com/content/18/0122/15/52920_72417340 3.shtml.

[2] Cai Fengming. (1997). The History of Games. Shanghai: Shanghai Literature press.

[3] Chinese Dictionary. https://www.zdic.net/hans/\%E6\%96\%97\%E6\%88\%8F.

[4] Chen Tongsheng as translator. (2016). Guoyu. Zhong Hua Press.

[5] Guo Dan, Cheng Xiaoqing and Li Binyuan as translators. (2016). Tso Chuan. Zhong Hua Press.

[6] Jin Yuelin, And Qian Gengsen. (1985). Chinese Philopsophy. Philosophical Research (09), 38-44.

[7] Ma Guojun. (1990). Chinese Traditional Games. Chinese Agriculture Press.

[8] Needham, Joseph. (1975). Science and Civilisation in China. Peking: Science Press.

[9] (Song Dynasty) Si Maqian, Li Hanwen. (2016). Historical Records. Beijing United Press.

[10] Wang Yandong as translator. (2019). Stratagems of the Warring States. Zhong Hua Press.

[11] Wang Chao as translator. (2015). Analects of Confucius. Beijing United Press.

[12] Wu Guosheng. (2006). The Concept of Time. Peking University Press.

[13] (Western Han Dynasty) Dai Sheng, and Liu Xiaosha as translator. (2015). Book of Rites. Beijing United Press.

[14] Wu Zimu, Zhouyou. (2000). Menglianglu. 21st Century Press.

[15] Zhang Hongiie. (2013). The Evolution of Chinese National Character. Hunan People's Publishing Press. 